\title{
Examining ERBB2 as a candidate gene for susceptibility to leprosy (Hansen's disease) in Brazil
}

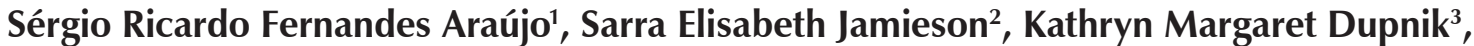 \\ Glória Regina Monteiro ${ }^{4}$, Maurício Lisboa Nobre ${ }^{4,5}$, Márcia Sousa Dias ${ }^{6}$, \\ Pedro Bezerra Trindade Neto ${ }^{7}$, Maria do Carmo Palmeira Queiroz ${ }^{8}$, Carlos Eduardo Maia Gomes ${ }^{4,9}$, \\ Jenefer Mary Blackwell2, Selma Maria Bezerra Jeronimo ${ }^{1,4,10 /+}$
}

\begin{abstract}
${ }^{1}$ Departamento de Bioquímica, Centro de Biociências ${ }^{4}$ Instituto de Medicina Tropical do Rio Grande do Norte ${ }^{7}$ Departamento de Clínica Médica, Centro de Ciências da Saúde ${ }^{8}$ Hospital Universitário Onofre Lopes ${ }^{9}$ Departamento de Biofísica e Farmacologia, Universidade Federal do Rio Grande do Norte, Natal, RN, Brasil ${ }^{2}$ Telethon Institute for Child Health Research, Centre for Child Health Research, University of Western Australia, Subiaco, Australia ${ }^{3}$ Division of Infectious Diseases, Weill Cornell Medical College, New York, NY, USA ${ }^{5}$ Hospital Giselda Trigueiro, Secretaria de Saúde do Estado do Rio Grande do Norte, Natal, RN, Brasil ${ }^{6}$ Faculdade de Medicina, Universidade do Estado do Rio Grande do Norte, Mossoró, RN, Brasil ${ }^{10}$ Instituto Nacional de Ciência e Tecnologia de Doenças Tropicais, Salvador, BA, Brasil
\end{abstract}

Leprosy remains prevalent in Brazil. ErbB2 is a receptor for leprosy bacilli entering Schwann cells, which mediates Mycobacterium leprae-induced demyelination and the ERBB2 gene lies within a leprosy susceptibility locus on chromosome 17q11-q21. To determine whether polymorphisms at the ERBB2 locus contribute to this linkage peak, three haplotype tagging single nucleotide polymorphisms (tag-SNPs) (rs2517956, rs2952156, rs1058808) were genotyped in 72 families (208 cases; 372 individuals) from the state of Pará (PA). All three tag-SNPs were associated with leprosy per se [best SNP rs2517959 odds ratio (OR) =2.22; 95\% confidence interval (CI) 1.37-3.59; $p=0.001]$. Lepromatous $(L L)(O R=3.25$; 95\% CI 1.37-7.70; $p=0.007)$ and tuberculoid $(T T)(O R=1.79 ; 95 \%$ CI 1.04-3.05; $p$ $=0.034$ ) leprosy both contributed to the association, which is consistent with the previous linkage to chromosome 17q11-q21 in the population from PA and supports the functional role of ErbB2 in disease pathogenesis. To attempt to replicate these findings, six SNPs (rs2517955, rs2517956, rs1810132, rs2952156, rs1801200, rs1058808) were genotyped in a population-based sample of 570 leprosy cases and 370 controls from the state of Rio Grande do Norte $(R N)$ and the results were analysed using logistic regression analysis. However, none of the associations were replicated in the RN sample, whether analysed for leprosy per se, LL leprosy, TT leprosy, erythema nodosum leprosum or reversal reaction conditions. The role of polymorphisms at ERBB2 in controlling susceptibility to leprosy in Brazil therefore remains unclear.

Key words: leprosy - genetic susceptibility - ErbB2 receptor - Brazil

Hansen's disease, or leprosy, is caused by infection with Mycobacterium leprae. The prevalence of Hansen's disease worldwide has decreased since the introduction of multidrug therapy (MDT) (Cartel et al. 1992). However, there continue to be new cases of Hansen's disease, with areas of active disease transmission (Subramanian et al. 2003); 232,857 new diagnoses of Hansen's disease were reported to the World Health Organization in 2012 (who. int/wer/2013/wer8835.pdf). In particular, Brazil continues to have one of the highest new case detection rates in the world (1.97/10,000 inhabitants), with 33,303 new cases reported in 2012 (who.int/wer/2013/wer8835.pdf).

In areas of higher endemicity, the majority of infections with M. leprae are asymptomatic (Fine 1983). The

doi: $10.1590 / 0074-0276130344$

Financial support: The Wellcome Trust (to JMB) and INCT-DT

SRFA and SEJ contributed equally to this work. JMB and SMBJ

contributed equally to supervision of the work.

+ Corresponding author:smbj@cb.ufrn.br

Received 28 June 2013

Accepted 13 November 2013 clinical disease develops along a spectrum from a T-helper (Th)1-predominant response causing one or a few skin lesions [tuberculoid (TT) form] to a Th2-predominant response with diffuse infiltrative disease [lepromatous (LL) form] (Walker \& Lockwood 2006). Patients with clinical forms between these two poles have borderline (BB) disease. Hansen's disease is curable with a six-12 month course of MDT, although the nerve damage due to demyelination is generally irreversible.

Within the first several days of therapy, there is a decrease in M. leprae transmission (Manglani \& Arif 2006). The clinical course for approximately $30 \%$ of patients with Hansen's disease is complicated by immune reactions (Beck-Bleumink \& Berhe 1992). Type 1, or reversal reaction (RR), often occurs in patients with BB forms of the disease, either at diagnosis or immediately after initiation of treatment and is characterised by an augmentation of the host immune response that results in swelling and inflammation of existing lesions with worsening nerve function (Trindade et al. 2010). A type 2 reaction, or erythema nodosum leprosum (ENL), causes systemic symptoms, such as fever, subcutaneous nodules and a vasculitis-like syndrome and is frequent in patients with the LL form (Sreenivasan et al. 1998). 
Several lines of evidence, including twin studies, genome-wide linkage and genome-wide association studies, indicate that host genetic factors are important in determining susceptibility to $M$. leprae (Casanova \& Abel 2002, Fernando \& Britton 2006, Berrington \& Hawn 2007, Zhang et al. 2009). The results of one genome-wide linkage study (Miller et al. 2004), together with detailed mapping (Jamieson et al. 2004), provided evidence for a cluster of leprosy and tuberculosis susceptibility loci on chromosome 17q11-q21. A role for genes encoding inducible nitric oxide synthase and chemokines within this region was proposed for tuberculosis (Jamieson et al. 2004), but the genes for leprosy have not been identified under this linkage peak. The ERBB2 gene, which encodes a member of the epidermal growth factor receptor family of receptor tyrosine kinases, lies within this region and has been shown to be important in M. leprae-induced Schwann cell demyelination (Tapinos et al. 2006). The binding of M. leprae to myelinated Schwann cells through ligation to the ErbB2 receptor results in Schwann cell demyelination and increases the population of de-differentiated Schwann cells. It is within these non-myelinated, de-differentiated Schwann cells that $M$. leprae preferentially proliferates (Tapinos et al. 2006). Therefore, the ErbB2 receptor is important in M. lepraeinduced demyelination and may represent a novel candidate underlying the 17q11-q21 linkage peak. The objective of this work was to examine whether polymorphisms in the $E R B B 2$ gene were associated with leprosy in primary and replication cohorts from northeastern Brazil.

\section{SUBJECTS, MATERIALS AND METHODS}

Subjects and study design - The primary cohort was comprised of 72 multicase leprosy families (372 individuals) (Table I) identified from medical records at local Ministry of Health centres in Belém, state of Pará (PA), Brazil and used in our earlier studies demonstrating linkage (Miller et al. 2004) and association (Jamieson et al. 2004) to genes in the chromosome 17q11-q21 region. Leprosy was diagnosed by highly experienced clinicians based on clinical examination for anaesthetic skin lesions, results from slit skin smear testing for acid-fast bacilli and, in some health centres, histological analysis. Patients were categorised into disease subtype groups according to the Ridley-Jopling histological scale (Ridley \& Jopling 1966) and/or bacterial load. These subtypes were LL, borderline lepromatous (BL), BB or borderline tuberculoid (BT)/TT. Information was not available on RRs or ENL in these patients. All families were of equivalent socioeconomic status. Blood was collected by venepuncture from all available family members and Epstein-Barr virus-transformed B cells were prepared, from which DNA was extracted for genetic analysis using a standard salting out procedure (Miller et al. 1988).

For replication of the results, a case-control study was performed (Table II). The study participants were people living in the state of Rio Grande do Norte (RN), where the leprosy detection rate has increased in the last 20 years (Queiroz et al. 2010, Moura et al. 2013). Controls were unrelated subjects who lived in a household with a leprosy case or were neighbours of a case, who had greater than three years of contact with a leprosy case. The diagnosis of leprosy was made by a Hansen's disease specialist and was based on clinical symptoms, skin smears and biopsy results. The leprosy was categorised based on the Ridley-Jopling classification (Ridley \& Jopling 1966), with patients characterised as LL, BL, $\mathrm{BB}, \mathrm{BT} / \mathrm{TT}$ or other clinical forms (neural, indeterminate or unclassified). Information regarding the treatment of RR or ENL was also recorded. Sociodemographic information was collected using a questionnaire. DNA was obtained from whole blood using a standard salting out procedure (Miller et al. 1988).

Ethical considerations - Informed consent was obtained from all study participants or their legal guardians. Ethical approval for the collection of samples from PA was obtained from the ethical review committee of the Evandro Chagas Institute (Belém) (Blackwell et al. 1997). Approval for the use of the samples in this study and for the collection and use of samples from $\mathrm{RN}$ was obtained from the Federal University of Rio Grande do Norte (CEP-UFRN 94-04) and the Brazilian National Ethical Committee (CONEP 11019). The certificate of ethical approval is 0042.0.051.051-09.

\section{TABLE I}

Family structures for the 72 families with leprosy cases collected from Belém, state of Pará, Brazil

\begin{tabular}{|c|c|c|c|}
\hline Family structure & $\begin{array}{l}\text { Leprosy } \\
\text { per se } \\
\text { (n) }\end{array}$ & $\begin{array}{c}\text { Leprosy LL } \\
\text { sub-type } \\
\text { (n) }\end{array}$ & $\begin{array}{l}\text { Leprosy TT } \\
\text { sub-type } \\
\text { (n) }\end{array}$ \\
\hline Families & 72 & 72 & 72 \\
\hline Nuclear families & 87 & $56^{a}$ & $48^{a}$ \\
\hline with 1 affected sib & 19 & 27 & 22 \\
\hline with 2 affected sibs & 50 & 25 & 17 \\
\hline with 3 affected sibs & 7 & 3 & 7 \\
\hline with 4 affected sibs & 5 & 1 & 1 \\
\hline with 5 affected sibs & 5 & 0 & 0 \\
\hline with 6 affected sibs & 0 & 0 & 1 \\
\hline with 7 affected sibs & 1 & 0 & 0 \\
\hline Affected offspring & 192 & 90 & 87 \\
\hline Affected parents & 41 & 25 & 10 \\
\hline Total affected individuals ${ }^{b}$ & $208^{c}$ & 109 & 93 \\
\hline Total individuals & 372 & 372 & 372 \\
\hline
\end{tabular}

$a$ : 17 nuclear families contain both lepromatous (LL) and tuberculoid (TT) affected individuals, therefore number of LL + TT nuclear families do not add up to leprosy per se; $b$ : due to pedigree structure some individuals are classed as both sibs and parents in different nuclear families, therefore the total number of affected is not the sibs + parents; $c$ : six leprosy per $s e$ individuals not classified as LL or TT, therefore numbers of affected children and parents for LL + TT do not add up to leprosy per se. Nuclear families with a single affected offspring were always part of an extended multicase pedigree. 
Genotyping - Initially, three haplotype tagging single nucleotide polymorphisms (tag-SNPs) (Table III) (rs2517956, rs2952156, rs1058808) across the ERBB2 gene were selected for genotyping in the primary cohort. An additional three SNPs (Table III) (rs2517955, rs1810132, rs1801200) were genotyped in the replication cohort. Two of the genotyped SNPs (Table III) (rs1801200 and rs1058808) have been shown to be associated with ErbB2 receptor dysfunction (Frank et al. 2005, Tong et al. 2009). Genotyping of the primary cohort was performed at the Cambridge Institute for Medical Research, Cambridge, UK, and was performed using TaqMan allelic discrimination technology (Applied Biosystems, Foster City, CA, USA) according to manufacturer's instructions. Genotyping of the replication cohort was carried out at KBiosciences (Hertfordshire, UK) using KASPar chemistry.

Statistical analysis - For the genetic analyses in the present study, LL/BL/BB and TT/BT subtypes were grouped at the LL (referred to hereafter as L) and TT (referred to hereafter as T) ends of the spectrum, respectively. Groups of patients with ENL and RR conditions formed a subset of other leprosy patients. SNPs were checked for Hardy-Weinberg equilibrium in unrelated founders in the primary cohort or in the control sample for the replication cohort, as appropriate.

For the primary cohort, Mendelian inconsistencies were identified in familial data using PedCheck software (O’Connell \& Weeks 1998) and removed prior to statis- tical analysis. Family-based association analyses were performed under an additive model using case/pseudocontrol (CPC) analysis (Cordell et al. 2004), wherein each affected offspring is matched with one to three pseudo-controls that are derived from the remaining possible genotypes of the parental mating. Odds ratios (OR), 95\% confidence intervals (CI) and p-values were calculated using robust conditional logistic regression models employing a robust sandwich estimator of variance and a Wald $\chi^{2}$ test statistic to control for clustering of trios within pedigrees. CPC was implemented in STATA v.10 (stata.com/). For the replication cohort, case-control association analyses were performed under an additive model using logistic regression (LOGIT) in STATA v.10, adjusting for covariates as indicated below. Results were recorded as OR with 95\% CI and associated p-values.

\section{RESULTS}

Characteristics of the populations studied - The characteristics of the Belém families used for the primary genetic association study of leprosy have been reported elsewhere (Jamieson et al. 2004, Miller et al. 2004). Table I provides information on the family structures for these pedigrees. As a family study, covariates that might influence leprosy infection are controlled for within the study design. The characteristics of the replication sample are presented in Table II. The use of a case-control design meant that it was important to determine whether there were covariates that should be taken into account in the logistic regression

TABLE II

Characteristics of case-control sample from the state of Rio Grande do Norte, Brazil

\begin{tabular}{|c|c|c|c|c|}
\hline \multirow[b]{2}{*}{ Variable } & \multirow{2}{*}{$\begin{array}{c}\text { Leprosy } \\
\text { n }(\%)\end{array}$} & \multicolumn{2}{|c|}{$\begin{array}{l}\text { Contact } \\
\mathrm{n}(\%)\end{array}$} & \multirow[b]{2}{*}{$\mathrm{p}$} \\
\hline & & Household & Neighbour & \\
\hline Sex (male/female) & $570(273 / 285)$ & $\begin{array}{c}129(46 / 83) \\
-\end{array}$ & $\begin{array}{c}- \\
237(77 / 160)\end{array}$ & $\begin{array}{c}0.0080^{a} \\
<0.0001^{a}\end{array}$ \\
\hline Age mean, years (range) & $44.09(10-98)$ & $\begin{array}{c}37.95(11-93) \\
-\end{array}$ & $38.39(10-92)$ & $\begin{array}{l}0.0016^{b} \\
0.0002^{b}\end{array}$ \\
\hline Education $(<$ high school $)$ & $396(79.8)$ & $\begin{array}{c}79(75.9) \\
-\end{array}$ & $164(75.9)$ & $\begin{array}{l}0.4254^{a} \\
0.2737^{a}\end{array}$ \\
\hline Time living in same household ( $>5$ years) & $357(74.4)$ & $\begin{array}{c}77(66.4) \\
-\end{array}$ & $\begin{array}{c}- \\
175(78.5)\end{array}$ & $\begin{array}{l}0.1030^{a} \\
0.2578^{a}\end{array}$ \\
\hline Family income $\left(<4\right.$ minimal wages $\left.{ }^{c}\right)$ & $378(90)$ & $\begin{array}{c}61(85) \\
-\end{array}$ & $200(87)$ & $\begin{array}{l}0.2146^{b} \\
0.2420^{b}\end{array}$ \\
\hline Lepromatous (LL/BL) & $186(32.7)$ & - & - & - \\
\hline Tuberculoid (BB/BT/TT) & $301(52.9)$ & - & - & - \\
\hline Other leprosy clinical forms & $45(7.9)$ & - & - & - \\
\hline Unclassified leprosy & $37(6.5)$ & - & - & - \\
\hline Erythema nodosum leprosum (ENL) & $70(12.3)$ & - & - & - \\
\hline Reversal reaction (RR) & $96(16.9)$ & - & - & - \\
\hline ENL and RR & $24(4.2)$ & - & - & - \\
\hline
\end{tabular}

$a$ : Fisher's exact test; $b$ : Student's $t$ test; $c$ : minimal wage in Brazil is about U\$56/week; BB: borderline; BL: borderline lepromatous; BT: borderline tuberculoid; LL: lepromatous; TT: tuberculoid. 
analyses for genetic associations. A detailed analysis of epidemiological risk factors for leprosy in the main site from which the replication sample was drawn, Mossoró, RN, has been reported elsewhere (Queiroz et al. 2010, Moura et al. 2013). In the current study, leprosy cases and controls (household and neighbour) had similar lengths of time living in the same house $(p=0.1030$ and $p=0.2578$, respectively), education ( $p=0.4554$ and $p=0.2737)$ and family income ( $p=0.2146$ and 0.2420 ) (Table II). In this study sample of 570 leprosy cases and 370 controls (Table II), there was a lower male-to-female ratio for controls compared to cases ( $p=0.0080$ and $p<0.0001$, respectively), likely due to a greater availability of females at the time of recruitment. The mean age of the cases (44.09 years; range 10-98 years), household controls (37.95 years; range 11-93 years) and neighbour controls (38.39 years; range 1092) also differed significantly ( $p=0.0016$ and $p=0.0002$, respectively). Sex, age at the time of collection, education status and family income were all included as covariates in the genetic association analysis for the replication cohort.
Association between ERBB2 polymorphisms and the risk of leprosy in the primary family-based cohort - Table IV summarises the results of the robust CPC analysis to search for associations between leprosy per se and leprosy subtypes in the primary family-based cohort from PA. All three SNPs show association with leprosy per se under an additive model. Analysis of clinical sub-types showed that both the LL and TT forms of leprosy contributed to the associations at two of the SNPs (rs2517956 and rs1058808), with the strongest signals for association observed for the combined leprosy per se phenotype. The application of a Bonferroni correction for three independent SNPs provides a significance cutoff of $p \leq 0.017$ (i.e., $p=0.05 / 3$ ), which is achieved for both rs2517956 and rs1058808 in this primary sample. SNP rs2952156 was significantly associated for the L sample, but not the T sample. Overall, the data from this family-based cohort from PA supported an association between polymorphisms at ERBB2 and the susceptibility to leprosy per se.

TABLE III

Details of ERBB2 single nucleotide polymorphisms (SNPs) genotyped

\begin{tabular}{lccccc}
\hline SNP rs\# & $\begin{array}{c}\text { Location } \\
\text { (build Hg19) }\end{array}$ & $\begin{array}{c}\text { Cohorts } \\
\text { genotyped }\end{array}$ & $\begin{array}{c}\text { Minor } \\
\text { allele }\end{array}$ & $\begin{array}{c}\text { Minor allele } \\
\text { frequency } \\
\text { (PA/RN) }\end{array}$ & Position/function \\
\hline rs2517955 & 37843931 & RN & C & 0.49 & Upstream region \\
rs2517956 & 37844109 & PA and RN & G & $0.38 / 0.38$ & Upstream region \\
rs1810132 & 37866255 & RN & C & 0.39 & Intronic \\
rs2952156 & 37877085 & PA and RN & A & $0.38 / 0.38$ & 0.15 \\
rs1801200 & 37879838 & RN & G & $0.49 / 0.50$ & Coding, non-synonymous (I655V) \\
rs1058808 & 37884287 & PA and RN & C & Coding, non-synonymous (P1170A) \\
\hline
\end{tabular}

a: now merged with SNP rs1136201. Cohorts are from states of Pará (PA) and Rio Grande do Norte (RN), Brazil.

\section{TABLE IV}

Robust case/pseudo-control (CPC) analysis for ERBB2 tagging single nucleotide polymorphisms (tag-SNPs) in primary families from the state of Pará, Brazil

\begin{tabular}{lcccccc}
\hline SNP & Phenotype & Allele & \# CPC sets & OR & 95\% CI & p \\
\hline rs2517956 & LL & G & 17 & 3.25 & $1.37-7.70$ & 0.007 \\
rs2952156 & LL & A & 18 & 2.75 & $1.15-6.55$ & 0.022 \\
rs1058808 & LL & C & 14 & 2.50 & $1.09-5.74$ & 0.031 \\
rs2517956 & TT & G & 27 & 1.79 & $1.04-3.05$ & 0.034 \\
rs2952156 & TT & A & 28 & 1.47 & $0.73-2.96$ & 0.284 \\
rs1058808 & TT & C & 25 & 2.08 & $1.13-3.85$ & 0.019 \\
rs2517956 & Leprosy per se & G & 47 & 2.22 & $1.37-3.59$ & 0.001 \\
rs2952156 & Leprosy per se & A & 50 & 1.84 & $1.00-3.39$ & 0.050 \\
rs1058808 & Leprosy per se & C & 39 & 2.18 & $1.28-3.74$ & 0.004 \\
\hline
\end{tabular}

robust CPC was used to analyse transmission of alleles at ERBB2 tag-SNPs (Table III) from heterozygous parents to lepromatous (LL), tuberculoid (TT) and leprosy per se individuals. CI: confidence interval; OR: odds ratio. 
ERBB2 polymorphisms and the risk of leprosy in the replication case-control cohort - Table $\mathrm{V}$ provides the results of the logistic regression analysis to search for associations between ERBB2 alleles and leprosy per se or leprosy sub-types in the replication case-control cohort from RN. None of the SNPs were associated with leprosy per se or with the TT or LL forms of leprosy, in this cohort (Table V). No association was observed for the ENL and RR groups compared to the non-ENL and non-RR controls (data not shown). Overall, the more heterogeneous population-based replication sample failed to replicate the associations between the polymorphisms at ERBB2 and any form of leprosy in RN.

\section{DISCUSSION}

The data presented here provide evidence for an association between polymorphisms in the ERBB2 gene and leprosy per se in a set of multicase families from PA, which we previously used to demonstrate a linkage between leprosy susceptibility and genetic markers at chromosome 17q11-q22 (Jamieson et al. 2004, Miller et al. 2004). However, this association between ERBB2 polymorphisms and leprosy was not replicated in a more heterogeneous population-based sample from RN. Given the larger sample size and thus the greater statistical power of this population-based study, the most parsimonious explanation for this failure to replicate the asso-

TABLE V

Logistic regression analysis for association between ERBB2 tagging single nucleotide polymorphisms (tag-SNPs) in cases and controls from the state of Rio Grande do Norte (RN), Brazil

\begin{tabular}{|c|c|c|c|c|c|c|c|}
\hline Marker & Phenotype & Allele & Case & Control & OR & $95 \%$ CI & $\mathrm{p}_{\text {adj }}$ \\
\hline rs 2517955 & LL & $\mathrm{C}$ & $299 / 628$ & $347 / 696$ & 0.89 & $0.70-1.13$ & 0.340 \\
\hline rs2517956 & LL & A & $397 / 646$ & $439 / 714$ & 0.97 & $0.76-1.24$ & 0.820 \\
\hline rs1810132 & LL & $\mathrm{C}$ & $230 / 640$ & $273 / 710$ & 0.88 & $0.68-1.12$ & 0.290 \\
\hline rs2952156 & LL & A & $229 / 646$ & $273 / 720$ & 0.88 & $0.69-1.13$ & 0.320 \\
\hline rs 1801200 & LL & A & $550 / 642$ & $611 / 716$ & 0.99 & $0.72-1.36$ & 0.970 \\
\hline rs1058808 & LL & $\mathrm{C}$ & $305 / 654$ & $357 / 720$ & 0.86 & 0.68-1.09 & 0.210 \\
\hline rs 2517955 & $\mathrm{TT}$ & $\mathrm{C}$ & $211 / 412$ & $347 / 696$ & 0.96 & $0.75-1.23$ & 0.740 \\
\hline rs 2517956 & $\mathrm{TT}$ & A & $243 / 412$ & $439 / 714$ & 1.10 & $0.86-1.41$ & 0.440 \\
\hline rs1810132 & TT & $\mathrm{C}$ & $163 / 412$ & $273 / 710$ & 1.04 & $0.81-1.34$ & 0.750 \\
\hline rs2952156 & TT & A & $166 / 416$ & $273 / 720$ & 1.08 & $0.84-1.39$ & 0.530 \\
\hline rs 1801200 & TT & A & $348 / 412$ & $611 / 716$ & 1.08 & $0.77-1.50$ & 0.660 \\
\hline rs1058808 & $\mathrm{TT}$ & $\mathrm{C}$ & $201 / 412$ & $357 / 720$ & 0.95 & $0.74-1.21$ & 0.670 \\
\hline rs2517955 & Leprosy per se & $\mathrm{C}$ & $558 / 1136$ & $347 / 696$ & 1.03 & $0.85-1.25$ & 0.758 \\
\hline rs2517956 & Leprosy per se & A & $697 / 1152$ & $439 / 714$ & 1.04 & $0.86-1.26$ & 0.672 \\
\hline rs1810132 & Leprosy per se & $\mathrm{C}$ & $432 / 1146$ & $273 / 710$ & 1.03 & $0.85-1.26$ & 0.742 \\
\hline rs2952156 & Leprosy per se & A & $433 / 1158$ & $273 / 720$ & 1.02 & $0.84-1.24$ & 0.817 \\
\hline rs1801200 & Leprosy per se & A & $976 / 1144$ & $611 / 716$ & 1.00 & $0.76-1.33$ & 0.991 \\
\hline rs1058808 & Leprosy per se & $\mathrm{C}$ & $564 / 1162$ & $357 / 720$ & 1.04 & $0.86-1.26$ & 0.655 \\
\hline rs2517955 & $\mathrm{RR}$ & $\mathrm{C}$ & $113 / 230$ & $372 / 758$ & 1.05 & $0.71-1.55$ & 0.820 \\
\hline rs2517956 & RR & A & $139 / 230$ & $468 / 776$ & 0.78 & $0.52-1.17$ & 0.230 \\
\hline rs1810132 & $\mathrm{RR}$ & $\mathrm{C}$ & $84 / 232$ & $294 / 770$ & 0.73 & $0.48-1.12$ & 0.140 \\
\hline rs2952156 & $\mathrm{RR}$ & A & $85 / 236$ & $291 / 774$ & 0.77 & $0.51-1.17$ & 0.220 \\
\hline rs1801200 & $\mathrm{RR}$ & A & $206 / 238$ & $649 / 764$ & 0.98 & $0.59-1.65$ & 0.950 \\
\hline rs1058808 & RR & $\mathrm{C}$ & $116 / 238$ & $376 / 780$ & 0.93 & $0.63-1.38$ & 0.720 \\
\hline rs2517955 & ENL & $\mathrm{C}$ & $79 / 174$ & $406 / 814$ & 0.88 & $0.55-1.40$ & 0.590 \\
\hline rs 2517956 & ENL & A & $113 / 180$ & $498 / 826$ & 0.93 & $0.58-1.47$ & 0.740 \\
\hline rs1810132 & ENL & $\mathrm{C}$ & $67 / 182$ & $311 / 820$ & 1.04 & $0.64-1.67$ & 0.890 \\
\hline rs2952156 & ENL & A & $63 / 176$ & $313 / 834$ & 1.03 & $0.64-1.68$ & 0.890 \\
\hline rs1801200 & ENL & A & $152 / 176$ & $703 / 826$ & 0.83 & $0.46-1.48$ & 0.520 \\
\hline rs1058808 & ENL & $\mathrm{C}$ & $84 / 182$ & $408 / 836$ & 1.02 & $0.65-1.62$ & 0.920 \\
\hline
\end{tabular}

logistic regression adjusted for all independent environmental covariates was used to assess association between $E R B B 2$ tagSNPs (Table III) and lepromatous (LL), tuberculoid (TT) or leprosy per se in case-control samples from RN. The frequencies of the alleles ( per $2 \mathrm{n}$ chromosomes successfully genotyped) for which odds ratios (OR) were determined are shown under the case and control columns.CI: confidence interval; ENL: erythema nodosum leprosum; RR: reversal reaction. 
ciation is that the positive finding in PA sample is due to a type I error. However, the a priori observation of a linkage between the susceptibility to leprosy per se and the chromosome 17q11-q22 region in this family-based study suggests that polymorphisms at ERBB2 could be contributing to the linkage peak in this relatively small series of large multicase families with a small number of founders derived from a focused geographical location in Belém (Jamieson et al. 2004, Miller et al. 2004). Indeed, ERBB2 lies directly under (i.e., within $700 \mathrm{~kb}$ of the top microsatellite marker in the linkage study) the linkage peak and is the most attractive candidate within this $<1 \mathrm{Mb}$ region. However, it has yet to be determined whether ERBB2 contributes functionally to leprosy susceptibility or is being carried on larger chromosome haplotypes transmitted within these families. Certainly, the broader $(\sim 26-46 \mathrm{Mb})$ linkage peak across the chromosome $17 \mathrm{q} 11-\mathrm{q} 22$ region is rich in immune response genes (e.g., NOS2A, the CCL chemokine cluster, CSF3, THRA/ ERBA1, CCR7, STAT5A/B, STAT3), multiple members of which could contribute to the linkage peak and could also act as candidate genes for leprosy susceptibility, as we demonstrated earlier for tuberculosis in this region of Brazil (Jamieson et al. 2004). Given estimates of linkage disequilibrium blocks for Caucasian and African populations (Gabriel et al. 2002), fine mapping by association analysis at the population level is only likely to be detected to within $<150 \mathrm{~kb}$. Therefore, the failure to replicate the association in a heterogeneous population-based sample might indicate that the gene contributing to leprosy susceptibility at chromosome 17q11-q22 in Brazil is not $E R B B 2$ itself. Further genetic and functional studies will be required to characterise the role of genes on chromosome 17q11-q22 in the susceptibility to mycobacterial disease in Brazil. For the moment, however, the role of $E R B B 2$ polymorphisms in determining the susceptibility to leprosy in Brazil remains ambiguous.

\section{ACKNOWLEDGEMENTS}

To the people from PA and RN, for their contribution to this study, to Manoel Gomes Fernandes, for his assistance during the field studies in RN, and to Dr Lúcio L Medeiros, Dr Mércia Souza and Goretti Oliveira, for their help in the studies in Mossoró.

\section{REFERENCES}

Beck-Bleumink M, Berhe D 1992. Ocurrence of reactions, their diagnosis and management in leprosy patient treated with multidrug therapy. Experience in the leprosy control programmer of the all Africa leprosy and reabilation Training center (ALERT) in Ethiopia. Int J Lepr 60: 173-184.

Berrington WR, Hawn TR 2007. Mycobacterium tuberculosis, macrophages and the innate immune response: does common variation matter? Immunol Rev 219: 167-186.

Blackwell JM, Black GF, Peacock CS, Miller EN, Sibthorpe D, Gnananandha D, Shaw JJ, Silveira F, Lins-Lainson Z, Ramos F, Collins A, Shaw M-A 1997. Immunogenetics of leishmanial and mycobacterial infections: the Belém family study. Philos Trans $R$ Soc Lond B Biol Sci 352: 1331-1345.

Cartel JL, Spiegel A, Ngoc LN, Moulia-Pelat JP, Martin PM, Grosset JH 1992. Leprosy in French Polynesia. The possible impact of multidrug therapy on epidemiological trends. Lepr Rev 63: 223-230.
Casanova JL, Abel L 2002. Genetic dissection of immunity to mycobacteria: the human model. Annu Rev Immunol 20: 581-620.

Cordell HJ, Barratt BJ, Clayton DG 2004. Case/pseudocontrol analysis in genetic association studies: a unified framework for detection of genotype and haplotype associations, gene-gene and gene-environment interactions and parent-of-origin effects. Genet Epidemiol 26: 167-185.

Fernando SL, Britton WJ 2006. Genetic susceptibility to mycobacterial disease in humans. Immunol Cell Biol 84: 125-137.

Fine PE 1983. Natural history of leprosy - aspects relevant to a leprosy vaccine. Int J Lepr Other Mycobact Dis 51: 553-555.

Frank B, Hemminki K, Wirtenberger M, Bermejo JL, Bugert P, Klaes R, Schmutzler RK, Wappenschmidt B, Bartram CR, Burwinkel B 2005. The rare $E R B B 2$ variant Ile654Val is associated with an increased familial breast cancer risk. Carcinogenesis 26: 643-647.

Gabriel SB, Schaffner SF, Nguyen H, Moore JM, Roy J, Blumenstiel B, Higgins J, DeFelice M, Lochner A, Faggart M, Liu-Cordero SN, Rotimi C, Adeyemo A, Cooper R, Ward R, Lander ES, Daly MJ, Altshuler D 2002. The structure of haplotype blocks in the human genome. Science 296: 2225-2229.

Jamieson SE, Miller EN, Black GF, Peacock CS, Cordell HJ, Howson JMM, Shaw M-A, Burgner D, Xu W, Lins-Lainson Z, Shaw JJ, Ramos F, Silveira F, Blackwell JM 2004. Evidence for a cluster of genes on chromosome 17q11-q21 controlling susceptibility to tuberculosis and leprosy in Brazilians. Genes Immun 5: 46-57.

Manglani PR, Arif MA 2006. Multidrug therapy in leprosy. J Indian Med Assoc 104: 686-688.

Miller EN, Jamieson SE, Joberty C, Fakiola M, Hudson D, Peacock CS, Cordell HJ, Shaw M-A, Lins-Lainson Z, Shaw JJ, Ramos F, Silveira F, Blackwell JM 2004. Genome-wide scans for leprosy and tuberculosis susceptibility genes in Brazilians. Genes Immun 5: 63-67.

Miller SA, Dykes DD, Polesky HF 1988. A simple salting out procedure for extracting DNA from human nucleated cells. Nucleic Acids Res 16: 1215.

Moura ML, Dupnik KM, Sampaio GA, Nobrega PF, Jeronimo AK, do Nascimento-Filho JM, Dantas RLM, Queiroz JW, Barbosa JD, Dias G, Jeronimo SM, Souza MC, Nobre ML 2013. Active surveillance of Hansen's disease (leprosy): importance for case finding among extra-domiciliary contacts. PLoS Negl Trop Dis 7: e2093.

O'Connell JR, Weeks DE 1998. PedCheck: a program for identification of genotype incompatibilities in linkage analysis. Am J Hum Genet 63: 259-266.

Queiroz JW, Dias GH, Nobre ML, Dias MCS, Araujo SF, Barbosa JD, da Trindade-Neto PB, Blackwell JM, Jeronimo SM 2010. Geographic information systems and applied spatial statistics are efficient tools to study Hansen's disease (leprosy) and to determine areas of greater risk of disease. Am J Trop Med Hyg 82: 306-314.

Ridley DS, Jopling WH 1966. Classification of leprosy according to immunity. A five-group system. Int J Lepr Other Mycobact Dis 34: 255-273.

Sreenivasan P, Misra RS, Wilfred D, Nath I 1998. Lepromatous leprosy patients show $\mathrm{T}$ helper 1-like cytokine profile with differential expression of interleukin-10 during type 1 and 2 reactions. Immunology 95: 529-536.

Subramanian M, Ali MKS, Thorat DM, Muthukumar M, Sathiskumar E, Ramadoss C, Khan MA 2003. Leprosy situation in endemic states of India and prospects of elimination of the disease. Indian J Lepr 75: 335-345. 
Tapinos N, Ohnishi M, Rambukkana A 2006. ErbB2 receptor tyrosine kinase signaling mediates early demyelination induced by leprosy bacilli. Nat Med 12: 961-966.

Tong SY, Ha SY, Ki KD, Lee JM, Lee SK, Lee KB, Kim MK, Cho CH, Kwon SY 2009. The effects of obesity and HER-2 polymorphisms as risk factors for endometrial cancer in Korean women. BJOG 116: 1046-1052.

Trindade MA, Benard G, Ura S, Ghidella CC, Avelleira JC, Vianna FR, Marques AB, Naafs B, Fleury RN 2010. Granulomatous reactivation during the course of a leprosy infection: reaction or relapse. PLoS Negl Trop Dis 4: e921.
Walker SL, Lockwood DN 2006. The clinical and immunological features of leprosy. Br Med Bull 77-78: 103-121.

Zhang FR, Huang W, Chen SM, Sun LD, Liu H, Li Y, Cui Y, Yan XX, Yang HT, Yang RD, Chu TS, Zhang C, Zhang L, Han JW, Yu GQ, Quan C, Yu YX, Zhang Z, Shi BQ, Zhang LH, Cheng H, Wang CY, Lin Y, Zheng HF, Fu XA, Zuo XB, Wang Q, Long H, Sun YP, Cheng YL, Tian HQ, Zhou FS, Liu HX, Lu WS, He SM, Du WL, Shen M, Jin QY, Wang Y, Low HQ, Erwin T, Yang NH, Li JY, Zhao X, Jiao YL, Mao LG, Yin G, Jiang ZX, Wang XD, Yu JP, Hu ZH, Gong CH, Liu YQ, Liu RY, Wang DM, Wei D, Liu JX, Cao WK, Cao HZ, Li YP, Yan WG, Wei SY, Wang KJ, Hibberd ML, Yang S, Zhang XJ, Liu JJ 2009. Genomewide association study of leprosy. N Engl J Med 361: 2609-2618. 